\title{
Genitourinary tract infections in pregnancy and low birth weight: case-control study in Australian Aboriginal women
}

\author{
Rosalie Schultz, Anne W Read, Judith A Y Straton, Fiona J Stanley, Patricia Morich
}

\begin{abstract}
Objective-To investigate the association between genital and urinary tract infections in pregnant Aboriginal women and low birth weight.

Design-Retrospective case-control study controlling for potential confounding variables.

Setting-Western Australia from 1985 to 1987.

Subjects-All Aboriginal women $(n=269)$ who had given birth to singleton infants weighing $2250 \mathrm{~g}$ or less (cases), and 269 randomly selected Aboriginal women who had given birth to singleton infants weighing $3000 \mathrm{~g}$ or more (controls).

Main outcome measures-Proportions of women in case and control groups who had had genital and urinary tract infections; odds ratios for low birth weight when genitourinary tract infection was present; population attributable fraction of low birth weight to genitourinary tract infection.
\end{abstract}

Results - At the time of delivery $51 \%$ of women in the case group (109/215) had genitourinary tract infections compared with $13 \%$ of controls (35/266). After controlling for potential confounding variables the odds ratio for giving birth to infants weighing $2250 \mathrm{~g}$ or less when genitourinary tract infection was present was 4.0 (95\% confidence interval $2 \cdot 3$ to $7 \cdot 0$ ). The proportion of infants with low birth weight attributable to genitourinary tract infection in the whole population of Aboriginal women was 32\% ( $95 \%$ confidence interval $17 \%$ to $49 \%$ ).

Conclusions-There was a strong association between low birth weight and the presence of genitourinary tract infections in Aboriginal women both during pregnancy and at the time of delivery. A community intervention trial of screening and treatment of genitourinary infections in this population is recommended.

\section{Introduction}

The poor state of health of Australian Aborigines has been well documented, ${ }^{12}$ and perinatal health in particular is worse in Aborigines than in non-Aboriginal Australians. ${ }^{3}$ Although only about $1 \%$ of the population of Australia is Aboriginal, $2 \%$ of live births are to Aborigines and $7 \%, 4 \%$, and $8 \%$ of stillbirths, neonatal deaths, and postneonatal deaths respectively occur in Aborigines. ${ }^{3}$ Preterm birth is thought to be an important factor in Aboriginal perinatal morbidity and mortality, some $16 \%$ of Aboriginal infants born in Western Australia being preterm during 1980-6 compared with $7 \%$ of all Western Australian infants. Recent research has focused on maternal genitourinary tract infections as potentially treatable causes of preterm birth.

Aboriginal women in Western Australia have a high prevalence of many established risk factors for preterm birth and high rates of genitourinary tract infections. Evidence of an association between genitourinary tract infections and preterm birth in Aboriginal women was suggested in a study which found that the regions of Western Australia with the highest proportions of preterm births to Aboriginal women were those in which the reported prevalence of genitourinary infections during pregnancy was also highest. ${ }^{6}$

This study was designed to investigate whether genital and urinary tract infections in pregnan Aboriginal women in Western Australia were associated with preterm birth, low birth weight ( $2250 \mathrm{~g}$ or less) being used as a measure of preterm birth.

\section{Subjects and methods}

The Western Australian maternal and child health research database was used as a sampling frame. This collection of data is based on the Western Australian midwives' notification of case attended form 2, which is a statutory document completed by the attending midwife on all deliveries of liveborn and stillborn infants in the state with a gestational age of 20 weeks or more or a birth weight of at least $400 \mathrm{~g}$. Demographic, medical, obstetric, and perinatal information is recorded for each birth, and about $99 \%$ of the 25000 births each year in Western Australia are recorded in this system. ${ }^{7}$ The notification system was validated in $1986^{8}$ and found to be accurate for most of the variables used in this study. Mother's race is determined by the midwife by prior knowledge, observation, or questioning. No distinction is made regarding degree of Aboriginality.

Ideally the case group would have consisted of mothers of all Aboriginal infants born before 37 weeks' gestation (preterm infants) and the control group of a matched random selection of mothers of Aboriginal infants born at 37 or more weeks' gestation (term infants). However, as data on gestational age for Aboriginal infants are unreliable and often unavailable ${ }^{69}$ it was necessary to infer maturity from birth weight. Thus cases were all Aboriginal women who had given birth to singleton infants weighing $2250 \mathrm{~g}$ or less in Western Australia from 1985 to $1987(n=269)$. We decided on three years of data as power calculations showed that this would be sufficient ( $80 \%$ power) to detect a $20 \%$ difference in the prevalence of infection between the two groups at the $5 \%$ level of significance.

The accepted international definition of low birth weight is less than $2500 \mathrm{~g} .{ }^{10}$ However, the difference in mean birth weight between infants born to white women and those born to Aboriginal women in Western Australia during the study years was roughly $250 \mathrm{~g}$ (maternal and child health research database, unpublished data). Thus a birth weight of $2250 \mathrm{~g}$ or less was chosen in an attempt to ensure that most births in this group were actually preterm.

Controls were randomly selected from all Aboriginal women who had given birth to singleton infants weighing $3000 \mathrm{~g}$ or more from 1985 to 1987 . This birth weight was chosen in an attempt to ensure that all the births in the group were full term. Controls were frequency matched ${ }^{11}$ with cases for year of birth and gender of infant.

A standard data collection sheet was used for collecting information from the hospitals where births occurred. Data for most of the pregnancies were collected by visiting hospitals ( 243 cases, 238 controls),
Ms Schultz, Department of Public Health. 
but for rural hospitals with fewer than five births in the study ( 26 cases, 31 controls) data were collected by mail. Data included information on genital and urinary tract infections during pregnancy and at delivery, other medical and obstetric conditions, previous obstetric history, smoking and alcohol consumption, and social and demographic variables. Hospital records, including paediatric assessments, were scrutinised to obtain the best estimate of gestational age for all infants, including previous births.

\section{DEFINITION OF INFECTION}

The doctors' diagnoses, as recorded in the notes, were used for all medical and obstetric conditions. For every genital tract, urinary tract, and other infection information was recorded about the site of the infection, the method and date of diagnosis, any organism(s) cultured or otherwise identified, whether and how treatment was given, and the results of any follow up tests. When no laboratory tests had been performed the method of diagnosis was recorded as "clinical signs." The coding of genitourinary tract infection as being present at the time of delivery was based on an incomplete course of treatment or a diagnosis made within one week of delivery for which no treatment was given.

We recognised that identifying an organism does not necessarily implicate that organism in infection, that infection may be present when no organism can be identified, and that infections may go unrecorded in pregnancy. However, as the above method is widely used in the diagnosis and treatment of infections in clinical practice we considered that it was appropriate to define infection in this way.

Data from hospital records, particularly those concerning tobacco and alcohol use, were supplemented by collecting information from antenatal records held by Aboriginal Medical Services. These organisations aim at providing culturally appropriate primary and preventive health care for Aboriginal people. ${ }^{12}$

Hospital and Aboriginal medical service data were then merged with data from the maternal and child health research database. Before analysis infants who were recorded as having birth weights of less than $500 \mathrm{~g}$ were excluded (18 cases) as these weights are known to be measured inaccurately and so that results would be comparable with those of other studies. ${ }^{10}$ Infants with major congenital malformations (21 cases, three controls) were also excluded as such malformations are known to be an independent cause of low birth weight. ${ }^{13}$ These infants were identified from the birth defects registry of Western Australia, ${ }^{14}$ which uses multiple sources of ascertainment up to the age of 6

TABLE I-Maternal characteristics

\begin{tabular}{|c|c|c|}
\hline Characteristic & $\begin{array}{l}\text { No }(\%) \text { of cases } \\
\quad(\mathbf{n}=215)\end{array}$ & $\begin{array}{c}\text { No (\%) of controls } \\
(n=266)\end{array}$ \\
\hline $\begin{array}{l}\text { Maternal age (years): } \\
\quad<20 \\
20-24 \\
25-29 \\
30-34 \\
\geqslant 35\end{array}$ & $\begin{array}{r}70(32 \cdot 6) \\
69(32 \cdot 1) \\
49(22 \cdot 8) \\
20(9 \cdot 3) \\
7(3 \cdot 3)\end{array}$ & $\left.\begin{array}{r}73(27 \cdot 4) \\
103(38 \cdot 7) \\
54(20 \cdot 3) \\
26(9 \cdot 8) \\
10(3 \cdot 8)\end{array}\right\} \chi^{2}=2 \cdot 96 ; \mathrm{df}=4 ; \mathrm{p}=0.56$ \\
\hline $\begin{array}{l}\text { Parity: } \\
0 \\
1 \\
2 \\
3 \\
4 \\
\geqslant 5\end{array}$ & $\begin{array}{l}67(31 \cdot 2) \\
59(27 \cdot 4) \\
33(15 \cdot 3) \\
22(10 \cdot 2) \\
21(9 \cdot 8) \\
13(6 \cdot 0)\end{array}$ & $\left.\begin{array}{l}71(26 \cdot 7) \\
68(25 \cdot 6) \\
55(20 \cdot 7) \\
35(13 \cdot 2) \\
17(6 \cdot 4) \\
20 \\
20 \cdot(7 \cdot 5)\end{array}\right\} \chi^{2}=5 \cdot 78 ; \mathrm{df}=5 ; \mathrm{p}=0 \cdot 33$ \\
\hline $\begin{array}{l}\text { Marital status: } \\
\text { Married/cohabiting } \\
\text { Single/divorced/widowed }\end{array}$ & $\begin{array}{l}111(51 \cdot 6) \\
104(48 \cdot 4)\end{array}$ & $\left.\begin{array}{l}145(54.5) \\
121(45.5)\end{array}\right\} \chi^{2}=0.29 ; \mathrm{df}=1 ; \mathrm{p}=0.59$ \\
\hline $\begin{array}{l}\text { Maternal height }(\mathrm{cm}): \\
<149 \\
150-159 \\
160-169 \\
>169 \\
\text { Unknown }\end{array}$ & $\begin{array}{r}3(1 \cdot 4) \\
81(37 \cdot 7) \\
88(40 \cdot 9) \\
6(2 \cdot 8) \\
37(17 \cdot 2)\end{array}$ & $\left.\begin{array}{rr}8 & (3 \cdot 0) \\
89(33 \cdot 5) \\
143(53 \cdot 8) \\
19(7 \cdot 1) \\
7(2 \cdot 6)\end{array}\right\} \chi^{2}=7 \cdot 76 ; \mathrm{df}=3 ; \mathrm{p}=0 \cdot 05$ (known values only) \\
\hline
\end{tabular}

years so that identification is as complete as possible. A further 15 women in the case group had no hospital records, so full data were available for 215 cases and 266 controls. For the logistic regression analyses this sample size of 481 was reduced to 410 because of missing data on maternal height, hypertension, or whether previous infants were preterm.

\section{STATISTICAL METHODS}

For categorical variables significant differences in proportions between the cases and controls were identified by $\chi^{2}$ test or Fisher's exact test when numbers in any cell were less than five. Student's $t$ test was used for continuous variables. ${ }^{15}$ Multiple logistic regression analysis with the CATMOD procedure in the SAS/PC statistical package ${ }^{16}$ was performed to determine the odds ratio for preterm birth when genitourinary tract infection was present at the time of delivery, and $95 \%$ confidence intervals were calculated.

Various models were fitted to the data simultaneously controlling for potential confounding factors which included known risk factors for preterm birth, such as adverse obstetric history and hypertension in pregnancy, ${ }^{17}$ and factors such as maternal height which had different distributions in the cases and controls. Screening for genitourinary tract infections was included in the model as a potential confounding factor as some women (for example, those with problems in previous pregnancies) are more likely than others to have been screened and thus identified as having infections. The matching variables of gender and year of birth of infant were included in the full regression models and subsequently eliminated as they did not significantly alter the odds ratios. Similarly, a quadratic term for maternal height was included in the models to allow for the possibility of a non-linear relation between maternal height and birth weight, but this also was removed as it did not significantly change the odds ratios.

In an attempt to ascertain the public health significance of genitourinary tract infections with regard to low birth weight in the total Aborigina population in Western Australia the percentage of preterm births attributable to genitourinary tract infections was calculated from the formula ${ }^{11}$. attributable fraction $=(O R-1) p /[(O R-1) p+1]$, where $\mathrm{OR}=$ odds ratio and $\mathrm{p}=$ proportion of total population exposed $(0 \cdot 158$ (from reference 6$)$ ).

\section{Results}

Determination of the best estimate of gestational age from hospital records, including early ultrasonography and Ballard assessments ${ }^{18}$ when these were available showed that $86 \%$ of infants born to mothers in the case group were judged to be preterm compared with $2 \%$ of infants born to controls. Hence our choice of birth weight criteria for selecting women having preterm births as cases and term births as controls was considered satisfactory.

Maternal characteristics of the cases and controls are shown in table I. There were no significant differences between the groups in maternal age, parity, or marital status, but the women in the case group were significantly shorter than controls (difference in mean height $1.2 \mathrm{~cm} ; \mathrm{p}<0.05$ ).

Data on smoking were available for only $146(68 \%)$ of women in the case group and $161(61 \%)$ women in the control group. Among this subsample there was no significant difference in smoking habits between the two groups, $96(66 \%)$ women in the case group and $93(58 \%)$ controls being smokers. Alcohol use was significantly better documented for women in the case group than the control group $(\mathrm{p}<0.05)$, data being available for $108(50 \%)$ women in the case group and 96 
TABLE II -Complications of pregnancy (some women had more than one complication)

\begin{tabular}{|c|c|c|c|}
\hline Complication & $\begin{array}{c}\text { No }(\%) \text { of } \\
\text { cases } \\
(\mathrm{n}=215)\end{array}$ & $\begin{array}{l}\text { No }(\%) \text { of } \\
\text { controls } \\
(n=266)\end{array}$ & $\mathrm{p}$ Value \\
\hline Anaemia ${ }^{\star}$ & $85(45 \cdot 7)$ & $90(45 \cdot 9)$ & $0 \cdot 97$ \\
\hline Antepartum haemorrhage & $39(18 \cdot 1)$ & $21(7 \cdot 9)$ & $<0 \cdot 01$ \\
\hline Diabetes $\dagger$ & $9(4 \cdot 6)$ & $11(4 \cdot 5)$ & 0.97 \\
\hline Hypertension $\ddagger$ & $52(24 \cdot 5)$ & $36(13 \cdot 7)$ & $<0.01$ \\
\hline \multicolumn{4}{|l|}{$\begin{array}{l}\text { Prolonged premature rupture of } \\
\text { membranes (longer than } 24\end{array}$} \\
\hline & $45(20 \cdot 9)$ & $7(2 \cdot 6)$ & $<0.001$ \\
\hline Threatened spontaneous abortion & $11(5 \cdot 1)$ & $1(0 \cdot 4)$ & $<0.01$ \\
\hline
\end{tabular}

*Data missing for 29 cases and 70 controls.

tData missing for 20 cases and 24 controls.

fData missing for three cases and three controls.

TABLE III - Genital and urinary tract infections diagnosed on separate occasions during pregnancy

\begin{tabular}{|c|c|c|}
\hline No and site of infections & $\begin{array}{l}\text { No }(\%) \text { of cases } \\
(\mathbf{n}=215)\end{array}$ & $\begin{array}{l}\text { No }(\%) \text { of controls } \\
\quad(n=266)\end{array}$ \\
\hline \multicolumn{3}{|l|}{ Genital tract infections: } \\
\hline 0 & $100(46 \cdot 5)$ & $176(66 \cdot 2)]$ \\
\hline 1 & $85(39 \cdot 5)$ & $68(25.6)\} \chi^{2}$ for trend $=16.38 ; \mathrm{df}=1 ; \mathrm{p}<0.001$ \\
\hline$\geqslant 2$ & $30(14 \cdot 0)$ & $22(8 \cdot 3)$ \\
\hline \multicolumn{3}{|l|}{ Urinary tract infections: } \\
\hline 0 & $141(65 \cdot 6)$ & $205(77 \cdot 1)]$ \\
\hline 1 & $55(25 \cdot 6)$ & $44(16.5)\} \chi^{2}$ for trend $=6.08 ; \mathrm{df}=1 ; \mathrm{p}<0.01$ \\
\hline$\geqslant 2$ & $19(8 \cdot 8)$ & $17(6 \cdot 4)]^{n}$ \\
\hline
\end{tabular}

TABLE IV - Prevalence of genital and urinary tract infections during pregnancy and at delivery

\begin{tabular}{|c|c|c|}
\hline & $\begin{array}{c}\text { No }(\%) \text { of cases } \\
\quad(n=215)\end{array}$ & $\begin{array}{l}\text { No }(\%) \text { of controls } \\
\quad(n=266)\end{array}$ \\
\hline \multicolumn{3}{|c|}{ Infections present during pregnancy: } \\
\hline None & $69(32 \cdot 1)$ & \multirow{4}{*}{$\gamma=28 \cdot 4 ; \mathrm{df}=3 ; \mathrm{p}<0.001$} \\
\hline Genital tract infection & $72(33 \cdot 5)$ & \\
\hline Urinary tract infection & $31(14 \cdot 4)$ & \\
\hline Both infections & $43(20 \cdot 0)$ & \\
\hline \multicolumn{3}{|c|}{ Infections present at delivery: } \\
\hline None & $106(49 \cdot 3)$ & \multirow{4}{*}{$\chi^{\prime}=79 \cdot 94 ; \mathrm{df}=3 ; \mathrm{p}<0.001$} \\
\hline Genital tract infection & $69(32 \cdot 1)$ & \\
\hline Urinary tract infection & $27(12 \cdot 6)$ & \\
\hline Both infections & $13(6 \cdot 0)$ & \\
\hline
\end{tabular}

$(36 \%)$ women in the control group. For the women for whom data were available significantly more women in the case group $(43 ; 40 \%)$ than in the control group (23; $24 \%)$ reported any alcohol consumption $(\mathrm{p}<0.05)$.

Many different medical conditions were recorded, including asthma, epilepsy, thromboembolism, and rheumatic heart disease, but the recorded prevalences of individual conditions were too small for analysis. A higher proportion of women in the case group than the control group had histories of preterm birth and spontaneous abortion. With regard to multiparous women data on previous births were unavailable for 12 cases and 12 controls, and for multigravid women data on previous pregnancies were unavailable for three cases and one control. Of the multiparous cases in which there were available data, 67 out of $133(50 \%)$ women had had a previous preterm birth compared with 23 out of 183 controls $(13 \%)(p<0.001) ; 51$ out of $151(34 \%)$ multigravid women among the cases had had a spontaneous abortion compared with 40 out of $198(20 \%)$ controls $(p<0 \cdot 005)$. More women among the cases than among the controls had hypertension, including both pregnancy induced and essential conditions; premature rupture of the membranes; antepartum haemorrhage; and threatened spontaneous abortion. Diabetes and anaemia, when recorded, were of a similar high prevalence in both groups of women (table II).

The most striking differences between the groups were in genital and urinary tract infections. A significantly higher proportion of women among the cases than among the controls had been diagnosed as having genital or urinary tract infections, or both, during pregnancy (146 (68\%) and $116(44 \%)$ respectively), and the women in the case group had had a significantly higher number of infections than the controls (tables III and IV). At the time of delivery $109(51 \%)$ women in the case group had a genitourinary tract infection compared with 35 (13\%) controls (table IV). There was no difference in the incidence of other infections between the two groups.

The organisms responsible for colonisation and 0 infection of the genital and urinary tracts at the time of delivery are shown in table $\mathrm{V}$. Trichomonas vaginalis; vaginosis with any of Gardnerella vaginalis, bacteroides species, or anaerobic streptococci; and group B streptococcus were significantly more common in the genital tract of women in the case group $(p<0.05)$. Escherichia coli was the only individual urinary tract $\bar{\nabla}$ pathogen significantly more commonly cultured from urine samples of women in the case group $(p<0.05)$.

Table VI shows the odds ratios for low birth weight among women with complications of pregnancy and $\overrightarrow{\vec{H}}$ other confounding variables when maternal height and $\stackrel{\sigma}{\sigma}$ age were controlled for. The odds ratio for low birth $\frac{\vec{\sigma}}{3}$ weight when genitourinary tract infection was present at delivery was $3.99\left(95 \%\right.$ confidence interval 2.28 to ${ }_{0}$ 6.99) after controlling for hypertension, antepartum haemorrhage, prolonged premature rupture of the membranes, threatened spontaneous abortion, adverse : obstetric history, and screening for infection.

The attributable fraction of low birth weight to 8 genitourinary tract infection in the Aboriginal population was calculated to be $32 \cdot 1 \%$ ( $95 \%$ confidence interval $16 \cdot 8 \%$ to $48 \cdot 6 \%$ ).

It has been suggested that threatened spontaneous abortion and prolonged premature rupture of the

TABLE $\mathrm{V}-$ Genital tract colonisation and bacteriuria: organisms reported at delivery (in many women colonisation was polymicrobial)

\begin{tabular}{|c|c|c|c|}
\hline Site and organism & $\begin{array}{c}\text { No }(\%) \text { of } \\
\text { cases } \\
(\mathbf{n}=215)\end{array}$ & $\begin{array}{l}\text { No }(\%) \text { of } \\
\text { controls } \\
(n=266)\end{array}$ & $\mathrm{p}$ Value \\
\hline \multicolumn{4}{|l|}{ Genital tract colonisation: } \\
\hline Candida albicans & $17(7 \cdot 9)$ & $15(5 \cdot 6)$ & $0 \cdot 42$ \\
\hline Trichomonas vaginalis & $17(7 \cdot 9)$ & $3(1 \cdot 1)$ & $<0.001$ \\
\hline $\begin{array}{l}\text { Vaginosis with any of Gardnerella } \\
\text { vaginalis, Bacteroides sp, or }\end{array}$ & & & \\
\hline anaerobic streptococci & $13(6 \cdot 0)$ & $3(1 \cdot 1)$ & $<0.01$ \\
\hline Group B streptococcus & $12(5 \cdot 6)$ & $4(1.5)$ & $<0.05$ \\
\hline Ncisseria gonorrhoeae & $3(1 \cdot 4)$ & $2(0 \cdot 8)$ & $0 \cdot 40$ \\
\hline Calymmatobacterium granulomatis & $1(0 \cdot 5)$ & $1(0 \cdot 4)$ & 0.69 \\
\hline Staphylococcus aureus & $2(0 \cdot 9)$ & 0 & $0 \cdot 20$ \\
\hline Others ${ }^{\star}$ & $7(3 \cdot 3)$ & $1(0 \cdot 4)$ & $<0.05$ \\
\hline $\begin{array}{l}\text { Unspecified or unknown } \\
\text { organismst }\end{array}$ & $18(8 \cdot 4)$ & $2(0 \cdot 8)$ & $<0.001$ \\
\hline \multicolumn{4}{|l|}{ Bacteriuria: } \\
\hline Escherichia coli & $14(6 \cdot 5)$ & $6(2 \cdot 3)$ & $<0.05$ \\
\hline Gram positive bacilli & $2(0 \cdot 9)$ & 0 & $0 \cdot 12$ \\
\hline Gram negative bacilli & $3(1 \cdot 4)$ & 0 & 0.08 \\
\hline Klebsiella sp & $2(0 \cdot 9)$ & $2(0 \cdot 8)$ & $0 \cdot 60$ \\
\hline Others $\ddagger$ & $4(1.9)$ & 0 & $<0.05$ \\
\hline $\begin{array}{l}\text { Unspecified or unknown } \\
\text { organismst }\end{array}$ & $15(7 \cdot 0)$ & $5(1 \cdot 9)$ & $<0.05$ \\
\hline
\end{tabular}

*Others were all those detected once only - namely, Clostridium perfringens, Klebsiella $\mathrm{sp}$, human papillomavirus, Treponema pallidum, Mycoplasma
hominis, herpes simplex virus, Torulopsis glabrata, Staphylococcusepidermidis. hominis, herpes simplex virus, Torulopsis glabrata, Staphylococcus epidermidis.
tIncludes all organisms detected in only one sample--namely, unclassified +Includes all organisms detected in only one sample--namely,
streptococci, Gram positive cocci, Enterobacter sp, Proteus sp.

$\neq$ Includes culture negative and uncultured urinary tract infections diagnosed by signs and symptoms.

TABLE VI-Logistic regression of genitourinary tract infection and potential confounding variables on low birth weight (based on $n=$ 410). (Results controlled for maternal height and age)

\begin{tabular}{|c|c|c|}
\hline Variable & Odds ratio & $\begin{array}{l}95 \% \text { Confidence } \\
\text { interval }\end{array}$ \\
\hline Hypertension & $2 \cdot 23$ & 1.22 to 4.07 \\
\hline Antepartum haemorrhage & 3.04 & 1.37 to 5.54 \\
\hline Prolonged premature rupture of membranes & $7 \cdot 36$ & 2.52 to 21.5 \\
\hline $\begin{array}{l}\text { Threatened spontaneous abortion } \\
\text { Adverse obstetric history (previous preterm }\end{array}$ & $14 \cdot 63$ & 1.55 to 137.9 \\
\hline $\begin{array}{l}\text { birth or spontaneous abortion) } \\
\text { Screening for infection (urine sample, }\end{array}$ & 3.66 & $2 \cdot 13$ to 6.30 \\
\hline vaginal swab, or both) & $2 \cdot 24$ & $1 \cdot 16$ to $4 \cdot 34$ \\
\hline Genitourinary tract infection at delivery & 3.99 & 2.28 to 6.99 \\
\hline
\end{tabular}


TABLE VII - Logistic regression of genitourinary tract infection and potential confounding variables on low birth weight excluding possible early manifestations of preterm birth (prolonged premature rupture of membranes and threatened spontaneous abortion) (based on $n=410$ ). (Results controlled for maternal height and age)

\begin{tabular}{lcc}
\hline Variable & Odds ratio & $\begin{array}{c}95 \% \text { Confidence } \\
\text { interval }\end{array}$ \\
\hline $\begin{array}{l}\text { Hypertension } \\
\text { Antepartum haemorrhage }\end{array}$ & 1.88 & 1.03 to 3.43 \\
$\begin{array}{l}\text { Adverse obstetric history (previous preterm } \\
\text { birth or spontaneous abortion) }\end{array}$ & 3.53 & 1.63 to 7.66 \\
$\begin{array}{l}\text { Screening for infection (urine sample, } \\
\quad \text { vaginal swab, or both) }\end{array}$ & 3.69 & 2.18 to 6.23 \\
Genitourinary tract infection at delivery & 2.35 & 1.23 to 4.50 \\
\hline
\end{tabular}

membranes may be early manifestations of preterm birth $^{19-21}$ and hence outcomes rather than confounding variables. Logistic regression analysis excluding these variables (table VII) showed a higher point estimate for the odds ratio of low birth weight with genitourinary tract infection at delivery of 4.83 (95\% confidence interval $2 \cdot 83$ to $8 \cdot 24)$. When threatened spontaneous abortion and premature rupture of the membranes were excluded as separate risk factors then the fraction of infants with low birth weight attributable to infections was $37 \cdot 7 \%$ (95\% confidence interval $22 \cdot 4 \%$ to $53 \cdot 4 \%$ ).

Logistic regression analysis was also performed for the subsample of women who had had spontaneous labour $(n=304)$ as women with induced labour or no labour may have had infants with low birth weight solely because of the induction or caesarean section. Infections remained a significant predictor of low birth weight with an odds ratio of 4.64 (95\% confidence interval $2 \cdot 31$ to $8 \cdot 61$ ).

\section{Discussion}

Established risk factors for preterm birth include extremes of maternal age, small stature, maternal smoking, unmarried status, low socioeconomic status, hypertension, previous preterm birth, and spontaneous abortion. ${ }^{17}$ Many of these factors cannot be altered after conception and others may be markers for a predisposition to preterm birth rather than causative factors. However, $60 \%$ of preterm births remain unexplained by these risk factors and efforts to identify and treat women at high risk of preterm birth have not significantly changed the proportion of women giving birth before term. ${ }^{21}$ In our study genitourinary tract infections were significant predictors of low birth weight - and, by implication, preterm birth-after controlling for many of these factors.

Our study showed a strong association between low birth weight and maternal genitourinary tract infections both during pregnancy and at delivery. This association remained when controlling for potential demographic, obstetric, and selective screening confounding factors. Infections were stronger predictors of low birth weight than any demographic or social factors measured, adverse obstetric history, and complications of pregnancy other than threatened spontaneous abortion and prolonged premature rupture of the membranes. Although socioeconomic status is difficult to measure, maternal height, which may be an indicator of this variable,,$^{22}$ was controlled for throughout.

When women who had had induced labours were excluded from the analysis infections remained a significant predictor of low birth weight, with an odds ratio higher than that for the total group. When threatened spontaneous abortion and prolonged premature rupture of the membranes were excluded as confounders from the analysis genitourinary tract infections became the strongest predictor of low birth weight of all the variables considered. These results support those of other studies which have shown a clear causative link between genitourinary tract infections and low birth weight or preterm birth..$^{23-26}$

Cultures of $T$ vaginalis, organisms of bacterial vaginosis, and group B streptococcus were significantly more frequent from women in the case group. These conditions have all been associated with preterm delivery and low birth weight in previous studies and share the characteristic of being sexually transmissible. ${ }^{212327}$

The high proportion of women in the case group with previous preterm deliveries or spontaneous abortions suggests an aetiological agent which could be recurrent or persistent, as is frequently the case with genital and urinary tract infections. This finding supports other studies which have shown that infectious organisms can cause spontaneous abortion by similar mechanisms to those which cause preterm labour..$^{28}$

In this sample of Aboriginal women treatment and follow up of infections was inadequate. Further research to determine the specific role of genitourinary tract infections in low birth weight and preterm birth in Aboriginal women is important if effective preventive measures are to be instituted. Clinical trials of screening for genitourinary infections and giving antibiotics in pregnancy would show whether there is a causal and preventable relation between infections and preterm birth in this population. The prevention and treatment of genitourinary tract infections during pregnancy have the potential to reduce the prevalence of low birth weight and preterm birth and to have an important impact on Aboriginal maternal, infant, and child health.

We are grateful to Drs Barry Garner and Nicholas de Klerk for statistical advice and to Ms Carol Garfield, Ms Maxine Croft, and Mr John Gibbins for computing assistance. We also thank the Health Department of Western Australia for access to midwives' notifications, Dr Charles Watson for support, and the Aboriginal Medical Services throughout Western Australia for their help. Financial support was received from the Wellcome Trust, United Kingdom, the Health Department of Western Australia, and the Australian Medical Association. The research for this paper was undertaken by RS for the bachelor of medical science (honours) degree in the Faculty of Medicine, University of Western Australia. This paper is publication number 80 of the Western Australian Research Institute for Child Health.

1 Thomson N. Review of available Aboriginal mortality data, 1980-1982. Med F Aust 1985;143:S46-9.

2 Thomson N. Aboriginal health-current status. Aust $N Z$ I Med 1984;14: 705-18.

3 Thomson N. Aboriginal infant mortality, 1976-1981. Australian Aboriginal Studies 1983;1:10-5

+ Kliewer EV, Stanley FJ. Aboriginal and white births in Western Australia 1980-1986. Part 1: birthweight and gestational age. Med J Aust 1989;151 493-502.

5 Leger WJ. Infection and premature labor. Am 7 Perinatol 1989;6:234-6.

6 Arturo ZC. The development and use of an Ahoriginal maternal and child health data base in Western Australia: maternal and infant health in Aboriginal communities 1981-1986 [master of public health thesis]. Perth: University of Western Australia, 1989:pp 127

7 Moore D. Perinatal statistics in Western Australia: fourth annual report of the Western Australian midwives' notification system 1986. Perth: Health Depart ment of Western Australia, 1988.

8 Hill C. Validation study of the Western Australian midwives' notification system 1986. Perth: Health Department of Western Australia, 1987.

9 Seward JF, Stanley FJ. Comparison of births to Aboriginal and caucasian mothers in Western Australia. Med f A ust 1981;ii:80-4.

10 Chiswick ML. Commentary on current World Health Organisation definitions used in perinatal statistics. Br $\mathcal{A}$ Obstet Gynaecol 1986;93:1236-8.

11 Schlesselman JJ. Case-control studies: design, conduct, analysis. Oxford: Oxford University Press, 1982.

12 Houston S. Aboriginal health. Med f A ust 1985; 143:S45.

13 Khoury MJ, Erickson JD, Cordero JF, McCarthy BJ. Congenital malformations and intrauterine growth retardation: a population study. Pediatrics 1988:82:83-90.

14 Bower C, Stanley F, Forbes R, Rudy E. Report of the congenital malformation registry of Western Australia 1980-1988. Perth: Health Department of Western Australia, 1988

15 Bland M. An introduction to medical slatistics. Oxford: Oxford University Press, 1987.

16 SAS Institute Inc. SAS procedures guide for personal computers, version 6 edition Cary, North Carolina: SAS Institute Inc, 1985

17 Creasy RK, Gummer BA, Liggins GC. System for predicting spontaneous preterm birth. Obstet Gynecol 1980;55:692-5.

18 Ballard JL, Novak KK, Driver M. A simplified score for assessment of fetal maturation of newly born infants. F Pediatr 1979;95:769-74. 
19 Toth $\mathrm{M}$, Witkin S, Ledger $\mathrm{W}$, Thaler $\mathrm{H}$. The role of infection in the etiology of preterm birth. Obstet Gynecol 1988;71:723-6.

20 Naeve RL, Peters EC. Causes and consequences of premature rupture of the membranes. Lancet 1980;: 192-4.

21 Wang E, Smaill F. Infection in pregnancy. In: Chambers I, Enkin M, Keirse MJNC, eds. Effective care in pregnancy and childbirth. Oxford: Oxfor University Press, 1989:534-64

22 Illsley R, Kincaid JC. Social correlations of perinatal mortality. In: Butler NR Bonham DG, eds. Perinatal mortality: the first report of the British perinatal mortality survey. Edinburgh: E and S Livingstone, 1963:270-86.

23 Investigators of the John Hopkins Study of Cervicitis and Adverse Pregnancy Outcome. Associations of Chlamydia trachomatis and Mycoplasma hominis with intrauterine

24 Romero $R$, Sirtori M O Oraun $E$, Avila $C$ Mazor M, Callahan R, at Infection and labor. V. Prevalence, microbiology and clinical significance of intra-amniotic fluid infection in women with preterm labur and intact membranes. Am f Obstet Gynecol 1989:161:817-24.

25 Romero R, Mazor M, Oyarzun E, Sirtori M, Wu YK, Hobbins JC. Is there an association between colonization with group $\mathrm{B}$ streptococcus and prematurity? J Reprod Med 1989;34:797-801.

26 Romero R, Oyarzun E, Mazor M, Sirtori M, Hobbins JC, Bracken M. Metaanalysis of the relationship between asymptomatic bacteriuria and preterm delivery/low birthweight. Obstet Gynecol 1989;73:576-82.

27 Lee MLF. Infections and prematurity: Is there a relationship? fournal of Perinatal and Neonatal Nursing 1988;2:10-20.

28 McGregor JA, French JL, Lawellin D, Todd JK. Preterm birth and infection: pathogenic possibilities. Am F Reprod Immunol Microbiol 1988;16 $123-32$

(Accepted 30 August 1991)

\title{
Risk of epilepsy after febrile convulsions: a national cohort study
}

\author{
C M Verity, Jean Golding
}

\section{Abstract}

Objective-To identify children with febrile convulsions, classify their febrile convulsions into simple and complex, and determine the number and type of subsequent afebrile seizures in those children.

Design - National population based study.

Setting-United Kingdom.

Subjects-16004 neonatal survivors born during one week in April 1970.

Main outcome measures-Information about febrile and afebrile seizures obtained from questionnaires at 5 and 10 years of age and from hospital records.

Results-Information was available for 14676 of the cohort children. $398(2.7 \%)$ of them had had at least one febrile convulsion. 16 children were known to be neurologically or developmentally abnormal before the first attack. Of the remaining $\mathbf{3 8 2}$ children, 305 had had a simple first febrile convulsion and 77 a complex first febrile convulsion. Thirteen of the $\mathbf{3 8 2}$ had had one or more afebrile seizures, nine of whom had developed epilepsy (recurrent afebrile seizures). A higher proportion of children with complex febrile convulsions $(6 / 95)$ rather than simple febrile convulsions (3/287) developed epilepsy, the risk being highest for those who had had focal febrile convulsions $\left(5 / 17 ; \chi^{2}=39.9, p<0.001\right)$. Three of the 32 children who had prolonged febrile convulsions developed afebrile complex partial seizures

Conclusions - The risk of epilepsy after febrile convulsions is much less than reported in many

\section{Definitions of convulsions}

Febrile convulsion-An event in infancy or childhood associated with fever but without evidence of intracranial infection or defined cause. This is similar to the National Institutes of Health definition. Children with previous afebrile seizures were excluded. Suspected seizures in the first four weeks of life were excluded but convulsions during vaccination fevers were included.

Department of Paediatrics, Addenbrooke's Hospital, Cambridge CB2 2QQ

C M Verity, FRCP, consultant paediatric neurologist

Institute of Child Health, University of Bristol, Bristol

Jean Golding, PHD, professor

Correspondence to: $\mathrm{Dr}$ Verity.

BMf 1991;303:1373-6

Complex febrile convulsion-Longer than 15 minutes, focal, or multiple (more than one convulsion per episode of fever).

Simple febrile convulsion-Not complex.

Recurrent febrile convulsion-More than one episode of fever associated with convulsions.

Afebrile convulsion-Classification based on proposals of the International League Against Epilepsy. Children with more than one afebrile attack defined as having epilepsy. hospital studies, and if febrile convulsions cause brain damage that leads to later epilepsy this is a rare occurrence.

\section{Introduction}

Hospital based studies have reported a high incidence of epilepsy in children after febrile convulsions - up to $40 \% .^{\prime}$ In contrast, population based studies suggest that the outcome is better, with incidences of $2 \%$ and $3.5 \%$ in two large American studies. ${ }^{23}$ Febrile convulsions may cause later afebrile seizures or some children may be predisposed to both febrile convulsions and subsequent afebrile seizures.

The child health and education study, ${ }^{45}$ which began as the British births survey, ${ }^{6}$ is one of the few cohort studies large enough to study outcome after febrile convulsions without the bias inherent in hospital based studies. We report the risk of afebrile seizures and epilepsy after febrile convulsions using data obtained when the cohort of children were aged 10 .

\section{Subjects and methods}

The British birth survey enrolled 16004 neonatal survivors $-98.5 \%$ of the infants born in the United Kingdom in one week in April 1970. Of these children, $13135(82 \%)$ were assessed at 5 years of age and 14902 $(93 \%)$ at 10 years. At the assessments parents were asked: "Has the child ever had any form of convulsion, fit, seizure or other turn in which consciousness was lost or any part of the body made an abnormal movement?" After the 10 years assessment replies to this question were available for 14676 children, of whom 1318 were judged to have had a suspicious event. Reported suspicious events were validated by sending questionnaires to general practitioners and by obtaining hospital records. Questionnaires were returned for $1212(92 \%)$ children and records obtained for $1173(89 \%)$. Children with confirmed febrile convulsions were classified according to the type of convulsion (box). Comparisons between groups were analysed by the $\chi^{2}$ test with Yates's correction.

\section{Results}

AGE OF ONSET, INCIDENCE, AND RECURRENCE OF FEBRILE CONVULSIONS

Of the 1318 children who had had suspicious events, 398 had had at least one febrile convulsion by 10 years of age (median (range) age of onset 1 year 7 months ( 2 months -7 years 9 months)). The remaining children had had other attacks such as breath holding attacks and afebrile seizures and will be discussed elsewhere. Two children who had had seizures and 